\title{
O DEVIR DE UM LIVRO-RAIZ: O DIÁRIO COMO APOIO À ESCRITA DE MARIA GABRIELA LLANSOL
} Tatiane da Costa Souza

a primeira imagem do Diário não é, para mim, o repouso na vida quotidiana, mas uma constelação de imagens, caminhando sobre as outras. [...] Eu diria: aqui está a raiz de qualquer livro. (Maria Gabriela Llansol)

Comecemos pela raiz, aquela que sustenta qualquer livro. Ao buscarmos tal palavra no dicionário, encontramos as seguintes definições para a mesma: "parte da planta que cresce para baixo, geralmente, dentro do solo, fixando-a e fornecendo-lhe água e os nutrientes que importam; [...] a parte inferior, base" (FERREIRA, 2010, p. 637). Se articularmos essas significações com as palavras de Maria Gabriela Llansol, presentes na epígrafe acima, poderemos pensar então que, se o diário, para a autora, não corresponde a um repouso na vida cotidiana, mas sim, a uma "constelação de imagens", que caminham umas sobre as outras, esse livro, como um Livro-raiz, poderia ser, justamente, aquele que dá apoio à escrita, ao alimentá-la, para que a mesma mantenha o fio de seu devir prosseguindo.

Nesse sentido, o diário llansoliano, como aquele que, de certa forma, ou, ainda, em sua forma, estrutura a obra, pode ser tomado ao modo vegetal, já que a escrita da autora referida é sempre atravessada por um movimento do "vivo", no qual não há um privilégio dos humanos, pois 
tudo participa da composição do texto - "o homem, a mulher, a paisagem" (LLANSOL, 2010, p. 44) -; tudo participa da composição do livro, inclusive, essa raiz, que é o diário, sempre atravessado pelo diverso que se metamorfoseia em puro acontecimento inesperado. Como Llansol (2011a, p. 50) observa: "a árvore é um livro que distribuiu as folhas pelos ramos de modo que nenhuma escape ao Sol; há um tal fulgor no sol que desce, e se esconde, que dificilmente posso concentrar-me sempre no mesmo lugar verde". Portanto, não se trata de centralizar o olhar/pensamento sempre no mesmo lugar, nos mesmos acontecimentos cotidianos, já que a própria raiz do diário parece ser aquela que alarga o volume da escrita, fazendo com que esta se abra para fora de si mesma, em um devir do tempo e do espaço.

A partir dessas considerações, pretendemos verificar, guiados por três movimentos, de que modo a construção do diário llansoliano, em sua forma singular de descontinuidade, pode ser justamente o fio que dá sequência à composição da "textualidade", ao criar, com rigor, um método de escrita.

\section{PRIMEIRO MOVIMENTO: PARTIR A ESCRITA AOS PEDAÇOS, ASSIM COMO SE PARTEM OS DIAS}

Em entrevista, concedida a Lucia Castello Branco, no ano de 1992, Maria Gabriela Llansol (2o11d, p. 48) diz: "O que escrevo é uma narrativa, uma só narrativa que vou partindo, aos pedaços”. Desse modo, como narrativa que se parte aos pedaços, pelas frações que dividem o tempo e o espaço, o texto llansoliano, apoiado na "constelação de imagens" que o atravessa, faz-se ao modo de um sonho - "sonho de que temos a linguagem" -, ${ }^{1}$ ao reunir textos e/ou fragmentos diversos, na busca pela composição da obra. No entanto, há nessa construção da narrativa uma operação que procura, pela "destituição da literatura", uma passagem para a margem da língua, ${ }^{2}$ deslizando da "narratividade" para aquilo que a autora nomeia como "textualidade".

É possível verificarmos essa construção, mais claramente, no discurso "Para que o romance não morra", proferido por Llansol, no ano

\footnotetext{
1 Essa formulação, que é título de um texto de Maria Gabriela Llansol, será trabalhada adiante.

2 Referimo-nos à frase de Maria Gabriela Llansol (2011a, p. 12): "destituo-me da literatura, e passo para a margem da língua”.
}

Remate de Males, Campinas-SP, v. 37, n. 1, pp. 159-173, jan./jun. 2017 
de 1991, por ocasião de um prêmio recebido pelo livro Um beijo dado mais tarde. Ao afirmar escrever para que o romance não morra, a autora propõe um deslocamento do "centro nevrálgico do romance" (LLANSOL, 1994, p. 120), instaurando uma mutação da narratividade, fazendo-a deslizar para a textualidade - um movimento que abre outro caminho ao texto: "ao novo, ao vivo, ao fulgor" (p. 120). Ao diferenciar a narratividade da textualidade, esse discurso llansoliano indica, também, aquilo que seria o "dom poético":

\begin{abstract}
A textualidade pode dar-nos acesso ao dom poético, de que o exemplo longínquo foi a prática mística. Porque, hoje, o problema não é fundar a liberdade, mas alargar o seu âmbito, levá-la até o vivo,

fazer de nós vivos no meio do vivo.

Sem o dom poético, a liberdade da consciência definhará. O dom poético é, para mim, a imaginação criadora própria do corpo de afetos, agindo sobre o território das forças virtuais, a que poderíamos chamar de existentes-nãoreais.

Eu afirmei que nós somos criados, longe, à distância de nós mesmos; a textualidade é a geografia dessa criação improvável e imprevisível; a textualidade tem por órgão a imaginação criadora, sustentada por uma função de pujança $o$ vaivém da intensidade. Ela permite-nos, a cada um por sua conta, risco e alegria abordar a força, o real que há-de vir ao nosso corpo de afectos (LLANSOL, 1994, pp. 120-121, grifos da autora).
\end{abstract}

Desse modo, Llansol cria uma escrita fundada no "dom poético" e uma comunidade de "existentes-não-reais", que busca, em um gesto de alargamento da escrita e do pensamento, abordar um "real que há-de vir ao corpo de afectos"; por isso, para a autora, "quando se escreve só importa saber em que real se entra, e se há técnica para abrir caminho a outros" (LLANSOL, 2011a, p. 52). Esse movimento do texto llansoliano, orientado pelas elaborações proferidas no discurso acima e guiado pela "geografia dessa criação improvável e imprevisível", cria, assim, uma "técnica” e/ou método que visa abrir caminho a outros, estendendo-se pelo prolongamento da obra, inclusive pela escrita dos diários.

Com relação à composição da escrita diarística de Maria Gabriela Llansol, cabe dizermos que a autora começa a escrever $O$ falcão no punho, seu primeiro diário publicado, em 1985, pouco tempo depois da escrita de O livro das comunidades; depois disso, vieram os diários Finita, em 1987, e Inquérito às quatro confidências, em 1997, e um texto chamado "O sonho de que temos a linguagem”, que são excertos extraídos de Inquérito às quatro confidências, não publicados nesse volume. Há, ainda, muitos escritos deixados por Llansol e que hoje compõem o seu espólio (setenta e 
seis diários numerados por ela, além de outros cadernos e outros registros, como folhas soltas datilografadas). ${ }^{3}$

Desse todo não todo que compõe a obra, há quase sempre o lugar e data em que os textos haviam sido escritos. De modo que, talvez, essa prática diária da escrita (o diário) tenha se tornado um método que possibilitava a Llansol dar continuidade aos seus livros - lugar em que "tudo está ligado a tudo e sem o tudo anterior não existe o tudo seguinte" (LLANSOL, 2011d, p. 51). Por isso, como observa Vania Baeta Andrade (2001, p. 16), "a distinção entre o que é diário e o que é ficção torna-se difícil e até mesmo inócua no universo llansoliano, onde ainda a própria categoria ficção cai em ruínas", ou seja, os diários são importantes para percebermos que a construção do texto llansoliano, como propõe Antônio Guerreiro (2014, p. 214), "nada tinha a ver com categorias como 'ficção' ou 'romance', e que estavam equivocadas todas as leituras que achavam que havia enigmas a decifrar, 'narrativas' a compor de maneira linear, personagens redutíveis a entidades romanescas". Nesse sentido, ao sair da escrita representativa, fazendo do próprio "vivido a matéria de sua obra" (p. 214), uma outra lógica se escreve na escrita diária llansoliana:

À medida que ousei sair da escrita representativa em que me sentia tão mal, [...] encontrei-me sem normas, sobretudo mentais. Nessas circunstâncias, identifiquei progressivamente "nós construtivos" do texto a que chamo figuras e que, na realidade, não são necessariamente pessoas mas módulos, contornos, delineamentos. Uma pessoa que historicamente existiu pode ser uma figura, ao mesmo título que uma frase ("este é o jardim que o pensamento permite"), um animal, ou uma quimera. $\mathrm{O}$ que mais tarde chamei cenas fulgor. $\mathrm{Na}$ verdade, os contornos a que me referi envolvem um núcleo cintilante. $\mathrm{O}$ meu texto não avança por desenvolvimentos temáticos, nem por enredo, mas segue o fio que liga as diferentes cenas fulgor. Há assim unidade, mesmo se aparentemente não há lógica, por que eu não sei antecipadamente o que cada cena fulgor contém. O seu núcleo pode ser uma imagem, ou um pensamento, ou um sentimento intensamente afectivo, um diálogo (LLANSOL, 2011a, p. 121).

Sem avançar por desenvolvimentos temáticos, muito menos por enredo, o texto llansoliano mantém a sua continuidade pelo fio que liga

\footnotetext{
3 Antes de sua morte, que aconteceu no ano de 2008, Llansol manifesta o desejo de publicar esses cadernos, chegando a acompanhar a transcrição do primeiro deles - nomeado por ela, de forma genérica, como Livro de horas. Esse trabalho, que hoje é feito pelo Espaço Llansol, já conta com a publicação de cinco desses diários: Uma data em cada mão - Livro de horas I (2010); Um arco singular - Livro de horas II (2011); Numerosas linhas - Livro de horas III (2013); A palavra imediata - Livro de horas IV (2014); O azul imperfeito - Livro de Horas $V$ (Pessoa em Llansol) (2015). Sobre isso, cabe conferir também o texto de Maria Carolina Fenati, intitulado "Um armário de fragmentos" (2014).
}

Remate de Males, Campinas-SP, v. 37, n. 1, pp. 159-173, jan./jun. 2017 
as diferentes "cenas fulgor", logo há uma unidade, mesmo que pareça não haver lógica, ou seja, o disperso aparenta ser um livro todo só. Como observa Maurice Blanchot (2005, pp. 345-346), um livro "será também sempre reunido em todas as direções, pela própria dispersão e segundo a divisão que lhe é essencial, que ele não faz desaparecer, mas aparecer, mantendo-a para nela se realizar". Ao estendermos esse pensamento à escrita do diário, cabe perguntarmos: será que esse fio que sustenta o texto, como um "fio-raiz", ligando as "cenas fulgor", é justamente aquele que faz prosseguir a escrita diária dos dias? Haveria, então, um apoio da obra nesse modo de contar os dias por escrito?

Sabemos que os dias servem para contar: horas, meses, anos. Mas o que contam todas essas frações do tempo e do espaço nos diários? Nesse sentido, ao falar da relação que o escritor estabelece consigo, Blanchot (2011, p. 20) diz da necessidade que alguns escritores têm de escrever diários. Assim, o diário já não é "essencialmente confissão, relato na primeira pessoa. É um memorial” (p. 2o), pois nele o escritor deve recordar-se de si mesmo, daquele que é quando vive sua vida cotidiana. No entanto, o meio pelo qual o escritor realiza isso "é, fato estranho, o próprio elemento do esquecimento: escrever. Daí que, entretanto, a verdade do diário não esteja nas observações e comentários interessantes, de recorte literário, mas nos detalhes insignificantes [...]" (p. 20).

Atentemo-nos, então, a este ponto: a insignificância. Serão, então, os detalhes insignificantes a nos serem contados pelos diários? Será essa parte anódina também um elemento essencial para que a "escrita dos dias"4 se mantenha? Encontramos em Blanchot (2005) uma formulação que nos permite avançar em relação a esse ponto. Segundo o autor, "o interesse do diário é sua insignificância. Essa é sua inclinação, sua lei. Escrever cada dia, sob a garantia desse dia e para lembrá-lo a si mesmo, é uma maneira cômoda de escapar ao silêncio" (p. 273). Parece ser dessa forma, então, como fruto da insignificância, que cada dia nos conta alguma coisa, pois "cada dia anotado é um dia preservado" (p. 273). Afinal, estamos sempre a contar coisas uns aos outros:

Peço-vos que atenteis neste ponto de partida: nós estamos sempre a contar coisas uns aos outros.

A maior parte das vezes, são histórias de furor e de sangue. Sabe-se. Mas não sempre. Às vezes, acontece-nos como acontece aos amantes nus que falam

4 Refiro-me à parte do título da tese de João Alves Rocha Neto (2015): A escrita dos dias: a ética da paisagem em Maria Gabriela Llansol. 
de coisas anódinas, pequenas confidências em troca, enquanto se acariciam e se contemplam.

Nesse instante, os corpos brilham

porque,

nesse trânsito, a palavra aí existe, mas sem importância útil, e os corpos, sem que nós o saibamos, a absorvem - e fulgem.

[...] Porque, por detrás das histórias, por detrás da magia do "era uma vez...", do exótico e do fantástico, o que nós procuramos são os estados do forado-eu, tal como a língua o indica, ao aproximar existência e êxtase, ao atribuir ao ser uma forma vibrátil de estar.

Na realidade, todos nós somos feitos, criados, longe, à distância de nós mesmos (LLANSOL, 1994, p. 118, grifos da autora).

Contar para que a palavra exista sem importância útil; contar "para que o romance não morra, mesmo se, para tal, ele tenha de mudar de forma” (LLANSOL, 1994, p. 116); contar para procurar nessa palavra anódina os "estados fora-do-eu", já que "todos nós somos feitos, criados, longe, à distância de nós mesmos” (p. 116, grifo da autora). Talvez seja por isso que a literatura interessava pouco para Llansol (2011a, p. 12), pois o que a convocava para essa experiência à "margem da língua", era justamente a proximidade-sobreposição:

[...] não posso escrever se não estiver próxima, coincidente. Com o meu olhar sobre o outro. Olhar no olhar do olhar sem fim. Procurar olhares, incluir e libertar olhares, entrar dentro de olhares paradoxais, sair deles, sofrer por ver, sorrir por ver ainda mais. [...] Todo romance é feito de fragmentos a que o autor apaga a data. Todo o romance tem por horizonte o autobiográfico onde o autor se esconde para tecer os fios de sua história como se fosse um outro e como se aquela aventura problema não fosse a dele, nem parte dela. [...] Muitas vezes é preciso esperar pelo passado para compreender o futuro. Outras vezes não. Que o tempo não conduz. Que o fio condutor está na lógica dos encontros (LLANSOL, 2011c, pp. 21-23).

Nesse olhar sem fim, lançado sobre o outro, parece se construir uma forma de condução da escrita: a de um olhar que, "des-possuído", renuncia a um eu absoluto, ao dar espaço para "um eu-passagem entre o eu e o outro" (LOPES, 1998, p. 25).

\section{SEGUNDO MOVIMENTO: DOBRAR O TECIDO DIÁRIO DOS DIAS SOBRE A PÁGINA DO LIVRO}

5 Essa ideia é trabalhada por Silvina Rodrigues Lopes (1998), no livro Teoria da despossessão: ensaios sobre textos de Maria Gabriela Llansol.

Remate de Males, Campinas-SP, v. 37, n. 1, pp. 159-173, jan./jun. 2017 
Em um fragmento datado de 7 de setembro de 1972, Llansol (2011a, p. 76) escreve: "o Diário é o pano com que se faz a limpeza dos anos; de mais real que os outros textos, é a sua configuração de moeda - o preço”. A partir dessa formulação da autora, podemos localizar aquele que seria o “método" para sua escrita, nomeado por ela de "sobreposição". Em O livro das comunidades, encontramos uma passagem em que Llansol (2014, p. 56), pela construção de um pensamento da escrita, que se guia pelo viés do bordado, indica como se construía esse "método":

bordo e penso que sei bordar; não sei como fiz essa associação mas logo depois reflito. Saber e ver. [...] Com um dedo sobre a linha, prendo também os olhos ao tecido; verifico que vejo um extenso panorama, meus olhos fixos no castanho aveludado parecem voltar-se para todos os lados; soergo a agulha do feltro, o movimento parece-me semelhante ao da escrita, embora inverso.

Não fui eu quem traçou este desenho que bordo, mas percorrendo-o com a agulha, reconstruo o nascimento do ato de desenhar; perco um pouco a noção do tempo como se o meu bordado tivesse vindo de um arquivo e estivesse prestes a desaparecer. Situo-me historicamente ao lado de outras mãos que bordariam tecidos de outra época. [...] Passo da escrita ao bordado, traduzindo como se ambos fossem a minha palavra; por momentos, esqueço-me mesmo de que bordo, de tal modo os meus dedos se tornaram dextros e o meu pensamento, reflectido sobre o bordado, um pensamento. Com um livro escreve-se outro livro. Como um livro é vegetal.

Saber e ver; prender os olhos ao tecido; perder a noção do tempo cronológico; passar da escrita ao bordado, como se passa de um livro a outro. Eis, aí, nesse gesto, uma forma de compor o texto - maneira peculiar pela qual outras mãos, vindas de fora, parecem se misturar às mãos da própria escritora, unindo tempos e espaços diversos, no côncavo dos dedos e das palavras. Como observa Karin Hopfe (2002, p. 182), "a sobreimpressão da escrita diarística quotidianamente recomeçada cumula as facetas do próprio devir do eu", um eu que, entregue "ao fascínio da ausência de tempo" (BLANCHOT, 2011, p. 21), retira-se em sua própria imagem e, nesse gesto, “o 'Eu' que somos reconhece-se a soçobrar na neutralidade de um 'Ele' sem rosto” (p. 21). No texto llansoliano, ao observamos tal movimento, rumo a um eu que se desvanece, percebemos também uma sobreposição de vozes, de objetos e de lugares, inaugurando um novo espaço textual.

Leio um texto e vou-o cobrindo com o meu próprio texto que esboço no alto da página mas que projecta a sua sombra sobre toda a mancha do livro. Esta sobreposição textual tem por fonte os olhos, parece-me que um fino pano 
flutua entre os olhos e a mão e acaba cobrindo como uma rede, uma nuvem, o já escrito (LLANSOL, 2014, p. 55).

Há, então, um fino pano que flutua entre os olhos e as mãos daquela que escreve, pano que abriga, com a limpeza dos anos, nesse ato de sobreposição, outras vozes, outros tempos, outros livros, outras leituras. Talvez por isso, um dia, Llansol (2014, p. 350) tenha escrito que mais do que Kafka ou V. Woolf, interessavam a ela agora os diários desses autores - "o duplo da obra em causa", ou, ainda, a dobra da obra em causa. Assim, os dias escritos, em sua dispersão, dobram-se uns sobre os outros e os textos, vindos dessa narrativa, que se parte aos pedaços, em pura dobra, ${ }^{6}$ amplificam-se. Como Llansol (2011b, p. 109) observa: "Penso como tudo depende do modo como manuseamos, porque é nesse manuseamento que tocamos, que tecemos a dobra, ou o mútuo. Tudo o que é, existe em dobra ou dobrado [...]".

Dessa forma, entre as dobras e os plissados, o texto, mesmo partido, continua. Em um fragmento datado de 12 de novembro de 1974, lemos sobre isso, a partir da experiência com o tempo, as palavras e as coisas:

Escrevo nestes cadernos para que, de facto, a experiência do tempo possa ser absorvida. [...] Em resumo: escrevo nestes cadernos para que não se afaste do meu corpo a linha montante que conduz à velhice, tal como a concebo: reflexão imensa, desprendimento obtido pelos contrastes, concentração no presente em que todos os tempos imagináveis já estão a desenrolar-se para sempre. Este estado é momento ideal para escrever.

[...] pus na mala um lenço encharcado de perfume que, em contacto com uma carta de minha mãe, escrita a tinta azul, fez várias manchas no papel. Uma delas é tão aliciante que vou guardá-la. Mas a carta quase já não posso relê-la; ainda são legíveis algumas palavras.

Quando não escrever em a Restante vida, que comecei hoje, escreverei aqui. De certeza que algumas palavras legíveis passarão de um a outro [...] (LLANSOL, 2011b, p. 14).

Assim, parece ser sempre na dobra de duas superfícies que algumas palavras legíveis, ao passarem de um texto ao outro, abrem espaços para a composição da obra, ou seja, como observa Myriam Ávila (2016, p. 121), "a escrita desguardada do diário, [...] pode ser transposta para o texto literário". Encontramos um pensamento próximo dessa ideia na tese de Janaína Rocha de Paula (2014). Ao trabalhar a noção de transposição, na

6 Sobre a composição do pensamento da dobra, na escrita de Maria Gabriela Llansol, cabe conferir o trabalho de Janaína Rocha de Paula (2014), desenvolvido em sua tese, intitulada Cor'p'oema Llansol. 
obra de Maria Gabriela Llansol, a autora avança em um pensamento da dobra.

Dobra: dobradura, marca de uma articulação leve, movimento, plissado. Dobrar não equivale a lançar-se a outro lugar. Dobrar equivale a abrir espaços no mesmo lugar, transpor e, assim, liberar, no oco da dobra, possibilidades inéditas. Além disso, nas dobras, redobras, dobras de dobras e desdobras, não se trata de conciliar os movimentos, os seus plissados. Elas são, então, um modo de lidar com isso - à maneira de um origami - que, mesmo dobrado, resta incompatível, irredutível. Nesse movimento, há algo que resiste, mas que se desloca, no exercício de transposição que se anuncia (PAULA, 2014, p. 12).

Dobrar: "abrir espaços no mesmo lugar"; transpor, para que sejam liberadas "possibilidades inéditas"; fazer com que a escrita resista à passagem do tempo. Portanto, nessa dobra dos dias, "o dia a dia (a que poderíamos chamar texto a texto) de Maria Gabriela Llansol acumula esses processos de sobreposição" (COELHO, 2014, p. 218, grifo do autor) e, por meio do infinito das constelações de imagens, abre caminho rumo ao desejo de um livro único; desejo de alcançar aquilo que seria o inalcançável: a própria obra - um "ponto que não se pode atingir, o único, porém, que vale a pena atingir" (BLANCHOT, 2011, p. 51).

\section{TERCEIRO MOVIMENTO: MANTER O FIO VIVO DA ESCRITA, PROSSEGUINDO ATÉ FORMAR UM LIVRO SÓ}

A fim de pensarmos esse terceiro movimento, partimos, primeiramente, do seguinte fragmento llansoliano, extraído de $\mathrm{O}$ começo de um livro é precioso:

O começo de um livro é precioso. Muitos começos são preciosíssimos.

Mas breve é o começo de um livro - mantém o começo prosseguindo.

Quando este se prolonga, um livro seguinte se inicia.

Basta esperar que a decisão da intimidade se pronuncie.

Vou chamar-lhe fio linha, confiança, crédito, tecido (LLANSOL, 2003, p. 1).

No prolongamento do tempo, escreve-se, então, um livro que "mantém o começo prosseguindo", fazendo com que outro livro se inicie - como "fio, __ linha, confiança, crédito, tecido". Cabe ressaltar que O começo de um livro é precioso é composto por 365 começos de livros possíveis, ou seja, poderíamos pensar que há, nesse deslocamento, um começo para cada dia do ano. No entanto, convém lembrar que todos 
eles se prolongam, ao formarem, em seu devir, um emaranhado de fios, construindo um diário de começos. É possível articularmos essa forma de composição do texto com a seguinte elaboração de Marcello Duarte Mathias (1997, p. 46): "escrita do efêmero, o diário é um dia que não tem fim. Não há capítulo final porque todas são, e nenhum o é”. Assim, diferentemente da autobiografia, que "é uma retrospectiva; o diário [é] um devir" (p. 46).

Parece haver, portanto, a consistência de uma incompletude, nesse movimento da escrita dos diários, que torna possível a continuidade dos textos, pois, como nota ainda Mathias (1997, p. 47), "narração irregular, constituída por fragmentos autônomos, o diário é um livro feito e ainda por se fazer [...]", ou seja, um livro "feito, sendo" (MALLARMÉ, 2010, p. 1730). ${ }^{7}$ Parece ser também nessa direção que podemos ler o seguinte fragmento de Llansol (2009, p. 115), datado de 4 de janeiro de 1976:

Todos estes textos integram o texto do meu livro. Livro único, que aparece publicado em lugares, datas, textos ou volumes diferentes.

O volume da escrita não me largava

Escrever para compor um livro único, que, ao se fazer, prolonga-se, alargando o volume da escrita, eis a incumbência de Llansol. Mas será que, nesse devir, haveria um tempo para os dias llansolianos se escreverem? Pois se o diário é aquele que "enraíza o movimento de escrever no tempo, na humildade do cotidiano datado e preservado por sua data" (BLANCHOT, 2011, p. 20), poderia haver um calendário exigido por esse Livro-raiz de Maria Gabriela Llansol? Em um fragmento datado de 27 de março de 1979, ela escreve:

Tal como sou acompanhada pelos lagos - águas adormecidas naturais e duráveis -, de igual modo deve fazer parte da sombra, que se desloca comigo, inscrever os dias estendidos por longo período de tempo.

No seu calendário deve impor-se imediatamente a noção de noite - uma semana, um mês, um ano de noites. Sem o calendário, o fluir do tempo deve parecer-lhe incomensurável, e tornar-se um obstáculo à separação clara entre as figuras que voltam em períodos (perigos) regulares do mesmo ponto de abóbada. Se geralmente os meses começam com a lua nova, ela atravessa outras épocas em que não tem outro sonho senão o de conhecer, e todos os livros, limites e indícios da vida quotidiana lhe parecem pequenos microcosmos

7 Referimo-nos ao desejo de Mallarmé (2010, p. 180) em compor um Livro Total - Livro absoluto -, pois, para o autor, "tudo, no mundo, existe para culminar num livro". 
justapostos com o mesmo fim, ou a mesma origem. É por isso particularmente importante a organização de um calendário que traga estabilidade ao meio, e dê proteção à Casa que, com sentido abissal, podia tornar-se o universo e desaparecer (LLANSOL, 2011a, pp. 9-10).

Há uma sombra que se desloca com aquela que escreve; há o desejo em inscrever os dias estendidos; há um prolongamento da noite que acompanha o texto. Afinal, no calendário dos dias llansolianos, a noção de noite deve se impor - "uma semana, um mês, um ano de noites". Portanto, mesmo que esse calendário se constitua de modo diverso, ao se nortear por um "véu [...] suspenso sobre a noite" (LLANSOL, 1997, p. 16), é preciso um espaço que traga estabilidade ao meio e dê proteção à Casa, pois sem ele, essa Casa, pela qual se faz a escrita, em seu sentido abissal, poderia desaparecer.

Nesse sentido, como propõe Antônio Guerreiro (1986, p. 68), “vivese no reino da simultaneidade, e o diário, em vez de estar orientado por uma cronologia, um fluir temporal, toma partido pelo percurso espacial". Ao seguir tal orientação, o movimento da escrita llansoliana, guiandose pela lógica de uma continuidade, parece ser aquele que, em meio ao devir da "noite obscura" (LLANSOL, 2006, p. 111), consegue criar imagens constelares, clarões descontínuos, "cenas fulgor", ou seja, o gesto de escrever diariamente, tomado ao modo de um calendário, pode ser o ponto de apoio que, ao reunir as noites e os dias em um espaço, acolha a escrita, protegendo-a. Como observa Blanchot (2011, p. 270), por mais livre que o diário seja, ao abrigar um fluxo descontínuo das mais diversas formas de pensamentos, há algo que nele deve ser respeitado:

O diário íntimo, que parece tão livre de forma, tão dócil aos movimentos da vida e capaz de todas as libertações, já que pensamentos, sonhos, ficções, comentários de si mesmo, acontecimentos importantes, insignificantes, tudo lhe convém, na ordem e na desordem que se quiser, é submetido a uma cláusula aparentemente leve, mas perigosa: deve respeitar o calendário. Esse é pacto que ele assina. O calendário é seu demônio, o inspirador, o compositor, o provocador e o vigilante. Escrever um diário íntimo é colocar-se momentaneamente sob a proteção dos dias comuns, colocar a escrita sob essa proteção, e é também proteger-se da escrita, submetendo-a à regularidade feliz que nos comprometemos a não ameaçar (BLANCHOT, 2011, p. 270).

Escrever é colocar-se sob a proteção dos dias, mesmo que eles sejam, como no calendário llansoliano, feitos de pura noite; escrever é colocar a escrita sob a proteção do calendário, ou, quem sabe, ainda, sob a proteção daquele que a sustenta: o diário. Assim, "estamos no ponto em que a noite 
alastra se não tiver o calendário dos dias ou mesmo a frieza dos números [...] e com a noite cresce o tecido da sombra, a incomunicabilidade encortiçada, o véu vidrado na loucura" (COELHO, 2014, p. 223). Nesse sentido, a composição do espaço da escrita llansoliana, lançada num tempo diverso, que adentra na noite, poderia ser pensada, como propõe a autora, ao modo de um estudo dos sonhos. Sobre isso, lemos:

A elaboração deste texto, se nós o estudarmos de um certo ponto de vista, tem as suas leis de desenvolvimento. É como o estudo dos sonhos. Com um só não chegamos a conclusão alguma, mas se houver uma sequência muito grande começamos a distinguir as leis que os regem (LLANSOL, 2009, p. 110).

Ao seguirmos essa orientação llansoliana, chegamos ao resto da sequência de um diário, ou, ainda, à restante sequência de um "sonho". Os excertos que compõem o artigo "O sonho de que temos a linguagem" faziam parte dos escritos de Inquérito às quatro confidências, mas, por considerar que "tirariam leveza e aceramento", Llansol (1997, p. 8) decidiu não os publicar no livro. Somente algum tempo depois, a pedido da Revista Colóquio-Letras, é que os excertos foram publicados em separado. Em um fragmento datado de 15 de outubro de 1996, lemos:

Sonho com o dia em que a presença que de nós ficará dos textos não será a do nosso nome próprio. Em que os signos da nossa travessia serão destroços de combate, toques de leveza o que eu esperava ficou,

ficou a chave, ficou a porta,

ficou a pedra dura ao luar (LLANSOL, 1997, pp. 16-18).

Há um sonho: a presença que de nós ficará dos textos não será a do nosso nome próprio, pois, do nome, parece restar apenas isto: "a pedra dura ao luar". Podemos analisar, também, o duplo sentido que a frase "o sonho de que temos a linguagem" evoca: o sonho de que possuímos a linguagem, mas também pode ser que, do sonho, só temos a linguagem. ${ }^{8}$ Como observa Lucia Castello Branco (2011, p. 52), "não é exatamente a literatura-sonho que nos interessa (a literatura que é sonho de que temos, possuímos a linguagem), mas tão somente a escrita, esta que 'resta sem resto’ de um sonho”. Assim, o que "parece haver de mais interessante neste

8 Sobre essa questão, Branco afirma (2011, p. 51): “O ‘sonho de que temos a linguagem' pode nos indicar também que, do sonho, temos (apenas) a linguagem, como a 'ponta de um véu'. Resta-nos, então, a linguagem a que o sonho se reduz. Ou, como bem indicou Freud em suas teorias, resta-nos apenas a escrita do sonho". 
um sonho de Llansol [...] é que, dele, só nos resta a linguagem, ou, mais propriamente, a escrita" (BRANCO, 2011, p. 52, grifo da autora).

Portanto, se o texto llansoliano é como o estudo dos sonhos, e se a escrita se realiza como sonho, ao dobrar os dias, os textos, as "cenas fulgor", compondo uma "constelação de imagens", é preciso que, mesmo na dispersão, haja uma raiz para que a escrita possa continuar; é preciso que, mesmo "des-datando" (LLANSOL, 2011c, p. 25), haja um calendário, para que a Casa da escrita, em seu sentido abissal, não desapareça; é preciso, pois, um Livro-raiz diário para que esse sonho, que é a escrita, seja anotado, dia após dia, não correndo o risco de desaparecer na imensidão desse véu suspenso sobre a noite. Assim, só poderíamos concordar com Llansol (2009, p. 19) sobre que o Diário, tomado em sua dimensão absoluta, ao modo mallarmaico, mais além do repouso na vida cotidiana, abriga aquela que seria, talvez, a sua maior "responsabilidade": fazer-se "raiz de qualquer livro".

\section{REFERÊNCIAS BIBLIOGRÁFICAS}

ANDRADE, Vania Baeta. Este é o jardim que o pensamento permite: fragmentos no litoral da textualidade Llansol. Dissertação de Mestrado em Teoria da Literatura. Faculdade de Letras, Universidade Federal de Minas Gerais, Belo Horizonte, 2001.

ÁVILA, Myriam Corrêa de Araújo. Diários de escritores. Belo Horizonte: Abre, 2016.

BARRENTO, João (Org.). O que é uma figura? Diálogos sobre a obra de Maria Gabriela Llansol na casa da saudação. Lisboa: Mariposa Azual, 2009.

BLANCHOT, Maurice. O livro por vir. Trad. Leyla Perrone-Moisés. São Paulo: Martins Fontes, 2005.

BLANCHOT, Maurice. O espaço literário. Trad. Álvaro Cabral. Rio de Janeiro: Rocco, 2011.

BRANCO, Lucia Castello. Chão de letras: as literaturas e a experiência da escrita. Belo Horizonte: Editora UFMG, 2011.

COELHO, Eduardo Prado. Maria Gabriela Llansol: o texto equidistante. In: FENATI, Maria Carolina (org.). Partilha do incomum: leituras de Maria Gabriela Llansol. Florianópolis: Editora da UFSC, 2014, pp. 217-224.

FENATI, Maria Carolina. Um armário de fragmentos. In: FENATI, Maria Carolina (org.). Partilha do incomum: leituras de Maria Gabriela Llansol. Florianópolis: Editora da UFSC, 2014, pp. 241-289. 
O devir de um livro-raiz: o diário como apoio à escrita de Maria Gabriela Llansol - 172

FERREIRA, Aurélio Buarque de Holanda. Mini Aurélio: o dicionário da língua portuguesa. Curitiba: Positivo, 2010.

GUERREIRO, Antônio. O texto nómada de Maria Gabriela Llansol. In: Revista Colóquio Letras, Lisboa, no 91, 1986, pp. 66-69.

GUERREIRO, Antônio. Apresentação. In: FENATI, Maria Carolina (org.). Partilha do incomum: leituras de Maria Gabriela Llansol. Florianópolis: Editora da UFSC, 2014, pp. 213-216.

HOPFE, Karin. A escrita no diário/o diário na escrita. In: BRAUER-FIGUEIREDO, Maria Fátima Viegas \& HOPFE, Karin (orgs.). Metamorfoses do Eu: o diário e outros gêneros autobiográficos na literatura portuguesa do século XX. Hamburg: Fundação Caluste Gulbenkian / Lisboa: Associação Luso-Hanseática, 2002, pp. 175-185.

LLANSOL, Maria Gabriela. Para que o romance não morra. In: . Lisboaleipzig $1-O$ encontro inesperado do diverso. Lisboa: Edições Rolim, 1994.

LLANSOL, Maria Gabriela. O sonho de que temos a linguagem. Revista Colóquio-Letras. Lisboa, nº 143-144, jan.-jun. 1997, pp. 5-18.

LLANSOL, Maria Gabriela. Onde vais, Drama-Poesia? Lisboa: Relógio D’Água, 2000.

LLANSOL, Maria Gabriela. O começo de um livro é precioso. Lisboa: Assírio \& Alvim, 2003.

LLANSOL, Maria Gabriela. Amigo e amiga - curso de silêncio de 2004. Lisboa: Assírio \& Alvim, 2006.

LLANSOL, Maria Gabriela. Uma data em cada mão - livro de horas I. Lisboa: Assírio \& Alvim, 2009.

LLANSOL, Maria Gabriela. Um falcão no punho: diário I. Belo Horizonte: Autêntica, 2011a.

LLANSOL, Maria Gabriela. Finita: diário II. Belo Horizonte: Autêntica, 2011 b.

LLANSOL, Maria Gabriela. Inquérito às quatro confidências: diário III. Belo Horizonte: Autêntica, 2011c.

LLANSOL, Maria Gabriela. Entrevistas/Maria Gabriela Llansol. Belo Horizonte: Autêntica, 2ond.

LLANSOL, Maria Gabriela. Cadernos inéditos. In: FENATI, Maria Carolina (org.). Partilha do incomum: leituras de Maria Gabriela Llansol. Florianópolis: Editora da UFSC, 2014 .

LLANSOL, Maria Gabriela. O livro das comunidades. Rio de Janeiro: 7letras, 2014. 
O devir de um livro-raiz: o diário como apoio à escrita de Maria Gabriela Llansol - 173

LOPES, Silvina Rodrigues. Teoria da des-possessão: ensaios sobre textos de Maria Gabriela Llansol. Porto: Black Sun Editores, 1998.

MALLARMÉ, Stéphane. Divagações. Trad. Fernando Scheibe. Florianópolis: Editora UFSC, 2010.

MATHIAS, Marcello Duarte. Autobiografias e diários. In: Revista Colóquio-Letras. Lisboa, no 143-144, jan.-jun. 1997, pp. 41-61.

PAULA, Janaína Rocha de. Cor'p'oema Llansol. Tese de Doutorado em Teoria da Literatura e Literatura Comparada. Faculdade de Letras, Universidade Federal de Minas Gerais, Belo Horizonte, 2014.

ROCHA NETO, João Alves. A escrita dos dias: a ética da paisagem em Maria Gabriela Llansol. Tese de Doutorado em Teoria da Literatura e Literatura Comparada. Faculdade de Letras, Universidade Federal de Minas Gerais, Belo Horizonte, 2015. 